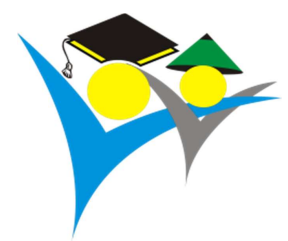

\title{
Pengelolaan Legum Penutup Tanah Untuk Meningkatkan Kualitas Tanah Di Aikmel Utara, Lombok Timur
}

\author{
Herman Suheri $^{{ }^{*}}$, Nurrachman ${ }^{1}$, Rukmini Kusmarwiyah $^{1}$, Mulat Isnaini ${ }^{2}$ \\ ${ }^{\text {I}}$ (Program Studi Agroekoteknologi, Fakultas Pertanian Universitas Mataram, Mataram - Indonesia; \\ ${ }^{2}$ (Program Studi Hama dan Penyakit Tanaman, Fakultas Pertanian Universitas Mataram, Mataram - Indonesia.
}

Article history

Received: 6 Desember 2021

Revised: 8 Desember 2021

Accepted: 21 Desember 2021

*Corresponding Author:

Herman Suheri,

Program Studi Agroekoteknologi,

Fakultas Pertanian Universitas

Mataram, Mataram - Indonesia

Email: herman.suheri@unram.ac.id
Abstract: Conventional agriculture has caused a decline in soil quality, and this is often not realized by farmers so that it tends to get worse over time. Through community service activities in the form of demonstration plots, farmers are introduced to alternative cultivation systems, which allow them to reduce the supply of production inputs from outside the farm. The alternative cultivation designed through this activity is a cultivation system on dry land that allows for integrated management of nutrients using cover crops as part of the cultural practices accompanied by the addition of organic matter available around the farm. The cover crop biomass is managed in an integrated manner with the crop cultivation system, namely by planting cover crops three weeks before planting the main crop (soybean), and ending it by cutting the entire biomass then adding it to the soil just before the soybean seeds are planted. As a comparison, organic matter in the form of compost or commercial organic fertilizer is applied to the soil prior the planting of soybean. At the end of the activity, a field day was held by inviting members of the partner farmer groups to witness the crop yields obtained from the demonstration plot plots. It is expected that farmers gain knowledge and raise their interest on the techniques for improving soil quality through the management of cover crops and organic materials in supporting environmentally friendly crop cultivation systems.

Keywords: demonstration plot; green soybean; cover crops; organic matter

Abstrak: Pertanian konvensional telah menimbulkan penurunan kualitas tanah, dan ini sering tidak disadari oleh petani sehingga cenderung menjadi makin parah dari waktu ke waktu. Melalui kegiatan Pengabdian Kepada Masyarakat dalam bentuk demplot, petani diperkenalkan dengan sistem budidaya alternatif' yang memungkinkan mereka mengurangi pemberian masukan produksi dari luar usaha tani. Budidaya alternatif yang dirancang melalui kegiatan ini adalah sistem budidaya di lahan kering yang memungkinkan dilakukannya pengelolaan hara secara terpadu dengan menerapkan penggunaan tanaman penutup tanah (cover crops) sebagai bagian dari praktik sistem budidaya disertai dengan penambahan bahan organik yang tersedia di sekitar lahan usaha tani. Biomassa tanaman penutup tanah dikelola secara terintegrasi dengan sistem budidaya tanaman, yaitu dengan menanam tanaman penutup tanah tiga minggu sebelum penanaman tanaman pokok (kedelai sayur), dan mengakhirkannya dengan cara memotong keseluruhan biomassa tanaman penutup tanah tersebut sebelum ditambahkan ke dalam tanah sesaat sebelum benih kedelai ditugal. Sementara itu sebagai pembanding, dilakukan pemberian bahan organik berupa kompos atau pupuk organik komersial dengan cara menebarkan langsung sesaat sebelum benih kedelai ditugal. Di akhir kegiatan, dilakukan field day dengan mengundang anggota kelompok tani mitra untuk menyaksikan hasil tanaman yang diperoleh dari petak demplot, sehingga diharapkan dapat menambah pengetahuan dan membangkitkan ketertarikan anggota kelompok tani dan masyarakat sekitarnya tentang teknik peningkatan kualitas tanah untuk budidaya melalui pengelolaan tanaman penutup tanah dan bahan organik dalam menunjang sistem budaya tanaman ramah lingkungan.

Kata kunci: demplot; kedelai sayur; tanaman penutup tanah (cover crops); bahan organik 


\section{PENDAHULUAN}

Dalam praktik budidaya dengan sistem konvensional, yaitu sistem budidaya yang dilakukan secara umum oleh masyarakat tani di Indonesia, termasuk di NTB, terjadi praktik pemberian masukan produksi dari luar (external input) dalam jumlah yang besar, antara lain dalam bentuk pemberian pupuk anorganik secara terus menerus, dan sering kali dalam takaran yang tinggi. Akibatnya terjadi penurunan kualitas tanah secara terus menerus karena sebagian besar bahan organik yang diproduksi dari suatu lahan, yang dapat berupa hasil panen dan seresah tanaman, diangkut keluar dari lahan tersebut tanpa diimbangi dengan pengembalian dalam bentuk bahan organik yang lain. Upaya perbaikan kualitas tanah sering kurang diperhatikan, karena sebagian besar petani tidak menyadari bahwa bahan organik di dalam tanah mempunyai peranan yang sangat penting dalam meningkatkan kualitas tanah, antara lain memperbaiki struktur tanah (Carter et al.,1994; Haynes, 2005, Krull et al., 2006; Oades, 1984; Tisdall \& Oades, 1982) untuk menstabilkan pH tanah, meningkatkan kapasitas tukar kation (Peverill et al., 1999) - yang mengarah kepada meningkatnya efisiensi penyerapan hara oleh tanaman, meningkatkan kemampuan tanah untuk menahan air - sehingga air lebih lama bertahan di dalam tanah, serta sebagai pemasok hara yang sangat lengkap kandungannya.

Mengingat pentingnya peran bahan organik bagi kesehatan tanah dan produksi tanaman, upaya yang mengarah pada peningkatan dan konservasi bahan organik tanah menjadi hal yang sangat perlu dilakukan. Dalam jangka pendek, salah satu praktik baik yang perlu dilakukan adalah dengan menambahkan bahan organik misalnya dalam bentuk kompos atau bentuk-bentuk bahan organik lain yang aman dan praktis dilakukan (DeBertoldi el al., 1987).

Namun demikian, jika petani melakukan pengembalian bahan organik, maka dalam praktik yang umum berlaku, petani harus mengambil bahan organik tersebut dari luar usaha tani. Misalnya, petani harus mendapatkan pupuk kandang dari lokasi yang makin jauh dari lokasi usaha tani tanaman, sehingga memerlukan pengangkutan yang dapat memberatkan petani untuk membiayainya.

Oleh karena itu, diperlukan solusi yang lebih rasional yaitu dengan pengelolaan tanaman penutup tanah yang dilakukan secara terintegrasi dalam suatu sistem budidaya tanaman (Clark, 2008; Ding et al., 2006; Sullivan, 2003). Saat ini penggunaan tanaman penutup tanah hanya terbatas pada tanamanm perkebunan seperti kakao (Baon \& Anugrina, 2006) kelapa sawit dan kopi (Ngawit, 2007). Penggunaan pada tanaman semusim hampir jarang dilakukan. Jika dilakukan, maka belum ditemukan cara pengelolaan yang baik agar penggunaan tanaman penutup tanah tersebut lebih efisien dan efektif dalam memberikan manfaat. Pada sistem budidaya jagung selain memberikan pengaruh positif terhadap lingkungan tanam, penggunaan tanaman penutup tanah yang berupa tanaman legum dapat mengurangi ketergantungan akan pupuk sintetik. Hasil Demplot yang dilakukan tahun 2018 di lahan dengan jenis tanah vertisol di Desa Pemongkong, Kecamatan Jerowaru, Lombok Timur (Suheri et al., 2018) menunjukkan bahwa pemberian bahan organik berupa campuran pupuk hijau dari tanaman penutup tanah kacang tunggak (Vigna unguiculata) dan kompos pada tanaman jagung yang hanya diberi separuh dosis pupuk mampu meningkatkan hasil tanaman jagung mencapai hasil yang setara dengan tanaman yang diberi pupuk sesuai dengan rekomendasi pemupukan penuh. Hasil ini menggambarkan bahwa dengan menggunakan pupuk hijau dapat dihemat penggunaan pupuk sintetik sampai dengan $50 \%$.

Diharapkan bahwa kegiatan yang berupa petak demonstrasi ini menjadi salah satu sumber informasi yang memberi motivasi kepada masyarakat tani di sekitar lokasi kegiatan untuk berupaya menerapkan penanaman tanaman penutup tanah dalam upaya meningkatkan kualitas tanah agar diperoleh hasil tanaman yang lebih tinggi.

\section{METODE}

\section{Rancangan Kegiatan dan Desain Demplot}

Kegiatan dibuat dalam bentuk Petak Demonstrasi (Demplot) dengan memilih tanaman kedelai sayur (edamame) sebagai tanaman pokok dan penggunaan legum penutup tanah (LPT) berupa kacang tunggak (Vigna unguiculata) sebagai sebagai sumber pupuk hijau, ditambah dengan penggunaan pupuk organik berupa kompos

yang dibuat dari biomassa tumbuhan yang terdapat di sekitar areal budidaya. Lahan Demplot disewa dari petani di Dusun Kekuang, Desa Aikmel, Kecamatan Aikmel Utara, Lombok Timur. Secara pedologi lahan di kawasan ini 
didominasi oleh tanah berpasir yang sudah mengalami degradasi yang cukup parah, sehingga dengan kadar bahan organik yang sangat rendah $(<0,5 \%)$. Hampir tidak ada petani di wilayah ini yang menambahkan bahan organik secara rutin ke dalam tanah pertanian mereka, dan hampir semua petani mengandalkan air hujan sebagai sumber pengairan terutama untuk tanaman-tanaman seperti jagung dan padi gogo.

Lahan tempat Petak Demonstrasi (Demplot) seluas sekitar $500 \mathrm{~m}^{2}$ dibagi menjadi 3 bagian masing-masing berukuran $10 \mathrm{~m} \times 15 \mathrm{~m}$. Ketiga bagian (petak) disiapkan untuk penanaman kedelai sayur dengan tiga skenario pengelolaan sebagai berikut. Petak pertama dengan menggunakan LPT yang berupa kacang tunggak, petak kedua dengan pupuk organik, dan petak ketiga dengan pupuk kimia sintesis yang sesuai dengan anjuran untuk varietas yang digunakan.

\section{Pengelolaan Legum Penutup Tanah (LPT) dan perlakuan pembanding}

Tanaman legum penutup tanah (LPT) berupa benih kacang tunggak (Vigna unguiculata) ditebar dengan takaran $10 \mathrm{~kg} / \mathrm{ha}$ (Gambar 1a). Setelah berumur 30 hari, LPT dipanen menggunakan mesin pemotong rumput rotary portable (Gambar 1b). Biomassa (seresah) LPT hasil pemangkasan ditebar kembali secara merata di atas lahan Demplot sebelum benih tanaman pokok (kedelai) ditugal (Gambar 1c,d). Biomassa dibiarkan melapuk secara alami untuk memungkinkan hara yang terkandung di dalamnya akan dilepaskan secara berangsur-angsur ke dalam tanah dan akan menyediakan hara bagi tanaman kedelai. Untuk mendapatkan gambaran mengenai kontribusi biomassa dari LPT, dilakukan estimasi dengan menimbang seresah segar dari cuplikan LPT yang diambil dari 5 posisi ubinan dalam petak masing-masing seluas $1 \mathrm{~m}^{2}$.

Kepada petak pembanding pertama dilakukan pemberian pupuk organik berupa sediaan komersial berbentuk granula (Petroganik, PT Petrokimia Gresik). Pemberian pupuk organik dilakukan dengan cara meletakkan pupuk organik tersebut pada lubang tugal sesaat sebelum benih kedelai dimasukkan ke dalam lubang tugal, sehingga secara keseluruhan jumlah pupuk organik yang diberikan ke petak pembanding setara dengan dosis $500 \mathrm{~kg} / \mathrm{ha}$.

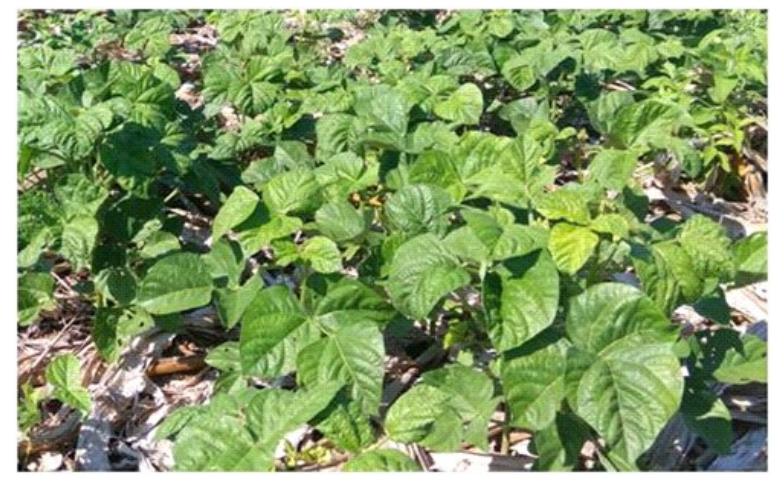

(a)

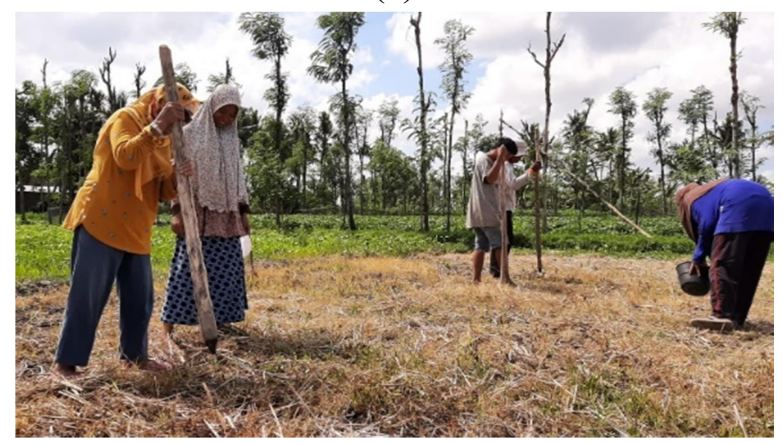

(c)

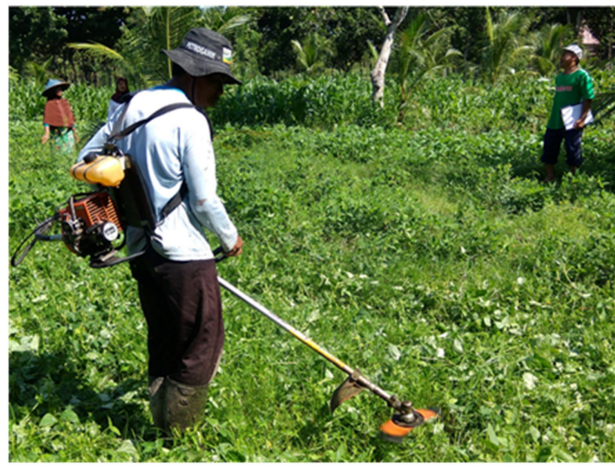

(b)

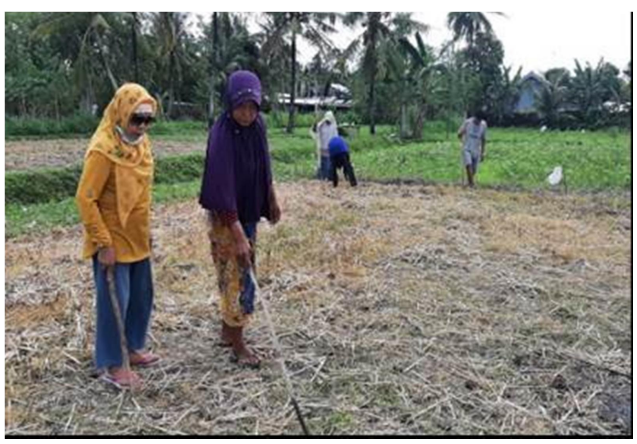

(d)

Gambar 1 .

Tanaman LPT yang ditebar sebelum penanaman tanaman pokok (a), lalu diterminasi dengan memotongnya menggunakan mesin pemotong rumput gendong (b). Setelah LPT melapuk dilakukan penugalan tanaan pokok, kedelai sayur (c dan d). 
Untuk petak pembanding kedua, pupuk kimia sintetis berupa SP36, Urea, dan $\mathrm{KCl}$ diberikan dengan dosis per hektar setara dengan $25 \mathrm{~kg} \mathrm{~N}, 50 \mathrm{~kg} \mathrm{P}_{2} \mathrm{O}_{5}$, dan $50 \mathrm{~kg} \mathrm{~K} 2 \mathrm{O}$ ). Keseluruhan dosis pupuk P dan $\mathrm{K}$ diberikan dalam larikan sesaat sebelum benih kedelai ditugal, sedangkan pupuk $\mathrm{N}$ diberikan dalam larikan setelah tanaman kedelai berumur dua minggu.

\section{Penanaman Tanaman Pokok (Kedelai Sayur)}

Seminggu setelah LPT dipangkas, lahan Demplot ditanami dengan tanaman kedelai sayur varietas Anjasmoro yang diperoleh dari Unit Pengelolaan Benih Sumber (UPBS), Malang. Benih ditugal (Gabar 1c,d) berjarak $20 \mathrm{~cm}$ di dalam baris dan $40 \mathrm{~cm}$ antar baris dengan orientasi Timur-Barat.

\section{Kegiatan penyampaian informasi kepada kelompok tani mitra}

Kegiatan penyampaian informasi kepada kelompok tani yang menjadi mitra dalam kegiatan ini dilakukan dalam dua tahap. Pada tahap pertama, kelompok tani diundang untuk diberi penyuuhan mengenai praktik pengelolaan tanaman dengan menggunakan legum penutup tanah yang mudah diperoleh dan secara ekonomis terjangkau oleh petani serta cara pengelolaannya untuk digunakan dalam sistem budidaya tanaman kedelai. Kegiatan ini dilakukan dalam bentuk ceramah oleh Tim Penyuluh, dan diikuti dengan tanya jawab.

Tahap kedua berupa kegitan Field Day. Pada acara Field Day anggota kelompok tani mitra diajak untuk menyaksikan pelaksanaan Demplot, dan langsung terjun ke lapangan untuk melaksanakan panen hasil Demplot.

\section{HASIL DAN PEMBAHASAN}

\section{Biomassa legum penutup tanah yang dihasilkan}

Legum penutup tanah berupa kacang tunggak yang ditebar pada petak demplot dengan dosis $10 \mathrm{~kg}$ benih per hektar menghasilkan biomassa setara dengan 34 ton/ha dan dilihat dari biomassa setelah dikeringkan setara dengan 5,5 ton/ha. Jika kandungan hara N, P, dan $\mathrm{K}$ dalam biomassa kering tanaman masing-masing adalah 1,6; 0,72; dan $0,89 \%$, maka sumbangan hara yang berasal dari legum penutup tanah kacang tunggak adalah masingmasing sekitar $90 \mathrm{~kg} \mathrm{~N}, 40 \mathrm{~kg}$ P, dan $50 \mathrm{~kg} \mathrm{~K}$ per hektar. Ini adalah jumlah yang cukup banyak. Namun demikian dalam proses pelapukannya, diduga terjadi kehilangan $\mathrm{N}$ yang cukup besar akibat penggunaan oleh mikroorganisme perombak. Namun demikian, pemberian biomassa tersebut tidak hanya bermanfaat sebagai penyumbang hara dalam jumlah yang cukup banyak ke dalam tanah, tetapi juga merupakan sumber bahan organik yang dapat memperbaiki kualitas tanah, sehingga tiga aspek yang menjadi indikator kualitas tanah yaitu aspek fisik di antaranya perbaikan struktur tanah yang membuat tanah menjadi lebih gembur, aspek kimia melalui penyediaan hara dan peningkatan kapasitas tukar kation di dalam tanah, dan dalam aspek biologi melalui peningkatan keragaman mikroba di dalam tanah akibat tersedianya bahan organik yang cukup untuk dijadikan sumber energi bagi mikroorganisme di dalam tanah.

\section{Hasil Demplot}

Setelah dilakukan penimbangan hasil panen kedelai sayur dari demplot, diperoleh bobot bersih kedelai (brangkasan kedelai sayur tanpa daun dan akar) per petak demplot adalah seperti yang disajikan pada Gambar 2a dan 2 b. Di sini dapat dilihat bahwa pemberian pupuk hijau berupa biomas dari legum penutup tanah sebelum dilakukan penananam kedelai, memberikan hasil yang hampir sama dengan penggunaan pupuk komersial, baik yang berupa pupuk organik (Petroganik), maupun yang berupa pupuk anorganik (NPK). Hal ini memberikan gambaran bahwa dalam keadaan sulitnya mendapat pupuk komersial dewasa ini, masih tersedia alternatif bagi petani untuk tetap mendapatkan hasil panen yang cukup dengan menggunakan legum penutup tanah sebagai bagian terintegrasi dalam sistem budidaya tanaman.

\section{Kegiatan penyuluhan}

Kegiatan penyuluhan dilakukan dalam dua tahap. Pada tahap pertama, kelompok tani diundang untuk diberi penyuuhan mengenai praktik pengelolaan tanaman dengan menggunakan legum penutup tanah yang mudah 
diperoleh dan secara ekonomis terjangkau oleh petani (Gambar 2). Kegiatan ini dilakukan dalam bentuk ceramah oleh Tim Penyuluh, dan diikuti dengan tanya jawab.

\section{Kegiatan Field Day}

Tahap kedua berupa Field Day. Pada acara Field Day para petani diajak untuk menyaksikan pelaksanaan Demplot, dan langsung terjun ke lapangan untuk melaksanakan panen hasil Demplot serta melakukan penimbangan hasil tersebut untuk mendapat gambaran mengenai hasil Demplot, dan menimbang hasil Demplot untuk mengetahui pengaruh pemberian biomassa LPT terhadap hasil tanaman kedelai dan perannya dalam mengurangi dosis pupuk untuk budidaya tanaman kedelai.

Untuk memberikan gambaran mengenai pengaruh pengelolaan LPT terhadap pertumbuhan tanaman kedelai para petani dapat langsung menyaksikan hasil Demplot. Mereka dapat menyaksikan perbedaan pertumbuhan tanaman kedelai antara ketiga skenario pengelolaan, dan dapat melihat hasilnya setelah di panen. Para peserta Field Day terlihat bersemangat mengikuti kegiatan penyuluhan, dan berharap dapat mencoba sendiri teknik yang didemonstrasikan di lahan masing-masing.

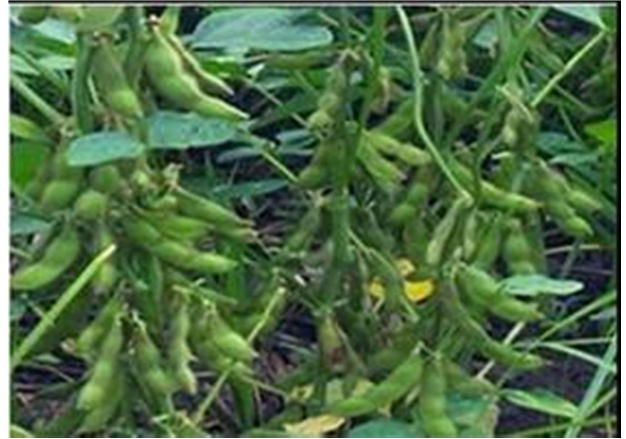

(a)

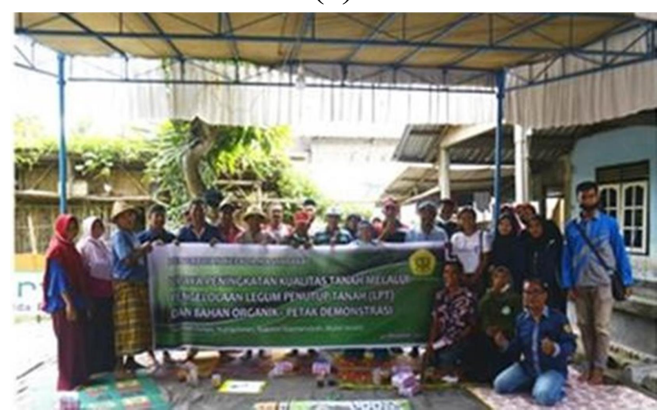

(c)

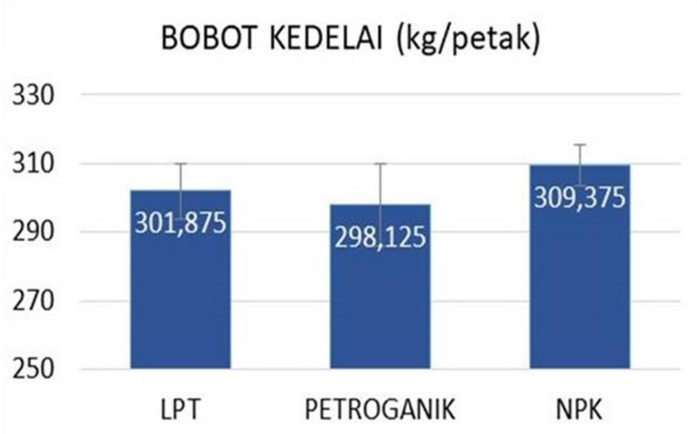

(b)

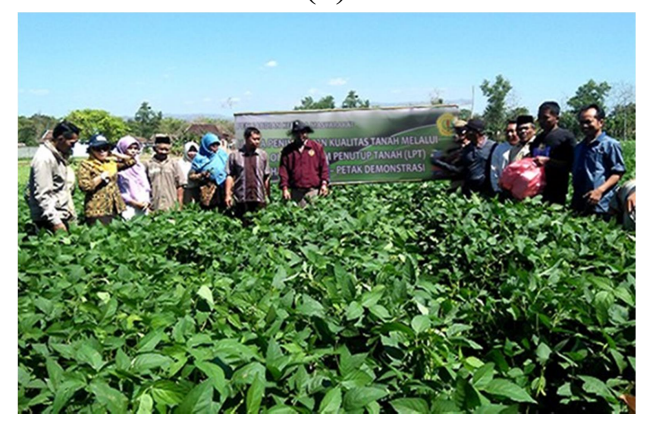

(d)

Gambar 2.

Hasil tanaman kedelai sayur yang diperoleh dari kegoatan Demplot (a) dan perbedaan bobot brangkasan per petak dari ketiga skeario perlakuan (b). Para petani melakukan foto bersama pada saat penyuluhan (c) dan pada saat Field Day (d).

\section{KESIMPULAN DAN SARAN}

Dapat disimpulkan bahwa kegiatan Pengabdian Kepada Masyarakat yang dikemas dalam bentuk Petak Demonstrasi telah berlangsung dengan baik. Tanaman penutup tanah (LPT) berupa kacang tunggak, dapat dijadikan salah satu alternatif yang reatif murah dalam pengelolaan bahan organik tanah dan pemasok hara untuk memperbaiki kondisi tanah dan untuk mengurangi penggunaan pupuk buatan. Manfaat LPT ini sudah terlihat dari hasil Demplot yang dilakukan, yaitu bahwa legum penutup tanah yang diberikan dengan dosis benih $10 \mathrm{~kg} / \mathrm{ha}$ selain dapat menyumbang hara yang cukup besar bagi tanah juga merupakan sumber bahan organik yang baik bagi perbaikan kualitas tanah. Hasil tanaman kedelai pada petak yang mendapatkan biomassa LPT yang pemangkasan pertamanya dilakukan pada ketinggian $20 \mathrm{~cm}$ dan $30 \mathrm{~cm}$ tetapi hanya diberi separuh dosis pupuk buatan, setara dengan hasil tanaman pada petak yang diberi dosis penuh tetapi tidak mendapatkan biomassa LPT. 
Disarankan agar tanaman pupuk hijau dibiarkan tumbuh melewati $20 \mathrm{~cm}$ sebelum dilakukan pemangkasan, agar ketika dipangkas setidaknya tersisa batang setinggi $20 \mathrm{~cm}$ sehingga tanaman pupuk hijau mempunyai sekurangnya dua buku untuk menghasilkan cabang baru yang akan menambah biomassa untuk dipanen sebagai pupuk hijau.

\section{Ucapan Terima Kasih}

Penulis mengucapkan terimakasih kepada Universitas Mataram yang sudah menyediakan dana melalui anggaran PNBP 2021 untk pelaksanaan kegiatan Pengabdian Kepada Masyarakat (PkM) yang berjudul: Upaya Peningkatan Kualitas Tanah Melalui Pengelolaan Legum Penutup Tanah (LPT) Dan Bahan Organik - Petak Demonstrasi Di Desa Aikmel Utara, Lombok Timur. Terima kasih yang sebesar-besarnya juga disampaikan kepada Kelompok Tani Makamur Jaya, Dusun Kekuang, Desa Aikmel Utara, Kecamatan Aikmel, Lombok Timur yang sudah bersedia menjadi mitra dalam pelaksanaan kegiatan PkM dan berkomitmen untuk menerapkan teknologi budidaya yang dihasilkan dari pelaksanaan PkM tersebut.

\section{Daftar Pustaka}

Baon, J.B. \& Anugrina, Y. 2006. Kajian Sifat Kompetisi Tanaman Penutup Tanah Arachis pintoi terhadap Pertumbuhan Tanaman Kakao. Pelita Perkebunan 2006, 22(3), 191-212.

Carter, M. R., Angers, D. A., and Kunelius, H. T. 1994. Soil structural form and stability, and organic matter under cool-season perennial grasses. Soil Science Society of America Journal 58, 1194-1199.

Clark, A. 2008. Managing TPT Profitably, 2nd Edition, Sustainable Agricultural Network, Handbook Series No. 3 , National Agricultural Library, Beltsville, MD 20705-2351. 212 pp. www.sare.org/publications/.

De Bertoldi, M., Fenranti, M.P. L'Henmite, P. and Zueeoni, F. (eds.). 1987. Compost Production, Quality and Use. Elsevier Applied Science, Landon, England.

Ding, G., Lie, X., Herbert, S., Novak, J., Amarasiriwardena, D., Xing, B., 2006. Effect of cover crop management on soil organic matter. Geoderma 130, 229-239.

Haynes, R.J. 2005. Labile organic matter fractions as central components of the quality of agricultural soils: an overview. Advaces in Agronomy 85:221-268.

Krull, E.S., Skjemstad, J.O. \& Baldock, J.A. 2006. Functions of Soil Organic Matter and the Effect on Soil Properties. GRDC Project No CSO 00029 Residue Management, Soil Organic Carbon and Crop Performance. http://grdc.com.au/uploads/documents/cso000291.pdf; Diakses : 21 Maret 2013.

Ngawit, I.K. 2007. Efikasi beberapa jenis herbisida terhadap tanaman penutup tanah Legumenosa di jalur tanaman kopi muda. Agroteksos 17(2)104-113.

Oades, J. M. 1984. Soil organic matter and waterstable aggregates in soils. Plant and Soil 76, 319-337.

Peverill, K. I., Sparrow, L. A., and Reuter, D. J. 1999. Soil Analysis. An Interpretation Manual. CSIRO Publishing: Collingwood.

Tisdall, J. M. and Oades, J. M. (1982). Organic matter and waterstable aggregates in soils. Journal of Soil Science $33,141-163$.

Suheri, H., I.K.D. Jaya, Gunartha, E.P. 2018. Pengelolaan Pupuk Hijau dan Penggunaan Bahan Organik dalam Sistem Budidaya Jagung - Petak Demonstrasi di Kecamatan Jerowaru Lombok Timur. Laporan Pengabdian Kepada Masysarakat yang dibiayai dengan Dana PNBP Universitas Mataram Tahun 2018.

Sullivan, P., 2003. Overview of Cover Crops and Green Manures. ATTRA National Sustainable Agriculture Information Service, 16 pp. www.attra.ncat.org/attra-pub/covercrop.html. 